\title{
Pär Magnus Olausson \\ Planning for resilience in the case of power shortage: The Swedish STYREL policy
}

\begin{abstract}
Modern society has developed a growing dependence on electricity in order to carry out important societal functions. This implies the risk of cascading failures to society in the case of power shortage. The creation of a resilient and sustainable power energy system is therefore crucial. Equal crucial is the preparedness for the event of power shortage. As a part of the Swedish crisis management system, the Swedish Energy Agency (EM) has developed a planning system, STYREL, to identify social important objects in order to ensure important social functions in the case of power shortage. This article examines STYREL as a policy network and as a planning system to ensure a sustainable and resilient power supply. The study focus on the design of the system, the implementation of the system based on the results from the two rounds completed in 2010 and 2014. Using interviews with coordinators at the local and regional level in three counties and a survey including all 21 coordinators at the regional level, it indicates that the design of the planning system reviles opportunities for improvements of the planning system. The study also indicates that the coordinators at the local level lack trust in the planning system depending on both the lack of resource and the lack of feedback. This in turn indicates challenges for the system from a resilient and sustainability point of view.
\end{abstract}

KEYWORDS: Public Policy; Policy Networks; Critical infrastructure protection; Crisis Management

RECEIVED 23 April 2018; ACCEPTED 9 January 2019.

\section{INTRODUCTION}

Electricity is a vital resource in today's society. The modern society is greatly dependent on electricity for the performance of important societal functions. It can be claimed that reliable electricity distribution is crucial to the survival and functionality of private households, businesses and public sector operations (Cohen, 2010; Ghanem et al., 2016), and the level of dependency on electricity is hardly likely to lessen with continued expansion of railways, the development of electric cars, etc. The electricity network is vulnerable to different types of events such as storms, floods, extreme weather situations and other extreme circumstances. These types of happenings could also increase in the future due to climate change. In addition to extreme weather conditions. The electricity network is also vulnerable because of outdated infrastructure, ageing components and vandalism.

Disruptions to the electricity network can lead to extensive problems for society. This has been a matter of concern not least in conjunction with major storms in Sweden such as Gudrun, Per, Dagmar and Ivar (see e.g. EM 2006; EM 2007). The creation of conditions for a sustainable electricity supply in the event of a crisis has therefore been an issue of great importance to the EM. STYREL is thus part of the Swedish crisis management system. This study Styrel as a planning process, the design of the system, the implementation and if the planning system contribute to a resilient electricity supply.

The Swedish crisis management system depart from three principles. The principle of responsibility means that the party who is responsible for an activity or process under normal conditions retains that responsibility during a crisis. The principle of similarity means that an operation or activity shall, to the greatest extent possible, function in the same way during a crisis as under normal conditions. Finally, the principle of proximity means that the actors closest to the crisis is responsible. This implies that the municipality or the county/region where the crisis occurs shall handle by the crisis. If the local resources are not sufficient, the state - primarily through the CAB - can provide assistance (see MSB, 2015; Tehler et.al. 2015). The CAB in each county is geographically responsible for its own region. Because areas of responsibility can overlap, there is often a great need for an exchange of information (see MSB 2015; Tehler et.al. 2015). In practice, this means that the CAB is responsible for coordinating the relevant actors within its county (MSB 2015). The role of coordinator can however, entail certain problems, since there is no express process for solving possible conflicts within the Swedish crisis management system. This becomes clear, for example, in a study of the Swedish Civil Defence Directors at the country's 21 CABs. Measures that would improve the possibility of achieving consensus between the various actors in the county 
is clearer governance, improved network management and increased resources. Furthermore, a number of Civil Defence Directors express the opinion that the Swedish crisis management system is characterised by weak governance and that it lacks continuity (Wimelius \& Engberg, 2015). Studies on the role of the regional climate and energy planning show that the role of the CAB is crucial for the implementation of a strategy. In order for the process to be accepted and to facilitate the implementation, the $\mathrm{CAB}$ needed lead the process and subsequently act as a meta-governor. When the CAB acted only partly or not at all as a meta-governor, the implementation process became more problematic. (see Palm \& Thoresson, 2014) A study of the river groups in northern Sweden also indicate a weak governance structure. The aim of the river groups is to exchange information through collaboration in networks in the event of floods and high river levels. The vague instructions from the Swedish Rescue Services Agency (a former government agency which merged into the newly formed MSB on 1 January 2009) has, however, implied that the various river groups work in different ways, have different points of focus for their collaboration, and include different actors (Olausson \& Nyhlén, 2017).

\section{STYREL - PLANNING FOR POWER SHORTAGE}

The EM is responsible for creating conditions for effective and sustainable energy use and the cost-effective distribution of Swedish energy (EM, 2012: 11). In the event of an electrical power shortage, it is necessary to perform a manual power cut ("MFK”). SvK is responsible for the power grid and is thus responsible for carry out a MFK. In the event of a power shortage, SvK order the power companies to carry out the MFK within 15 minutes (FOI, 2013: 15; EM 2013: 11).

In order for SvK and the power companies to perform an MFK without negatively affecting any of society's central functions, the EM, together with MSB and SvK has designed a planning and prioritisation process called STYREL (a Swedish acronym for Steering of electricity to prioritised users during short-term electricity shortages). (See SFS 2011:931) on planning for prioritisation of vital electricity users in society). Styrel has been implemented twice, the first round in 2010 and the second round in 2014 and a third is planned for 2019. The planning process follows seven steps, see figure 1.

Fig. 1: Styrel - The Process

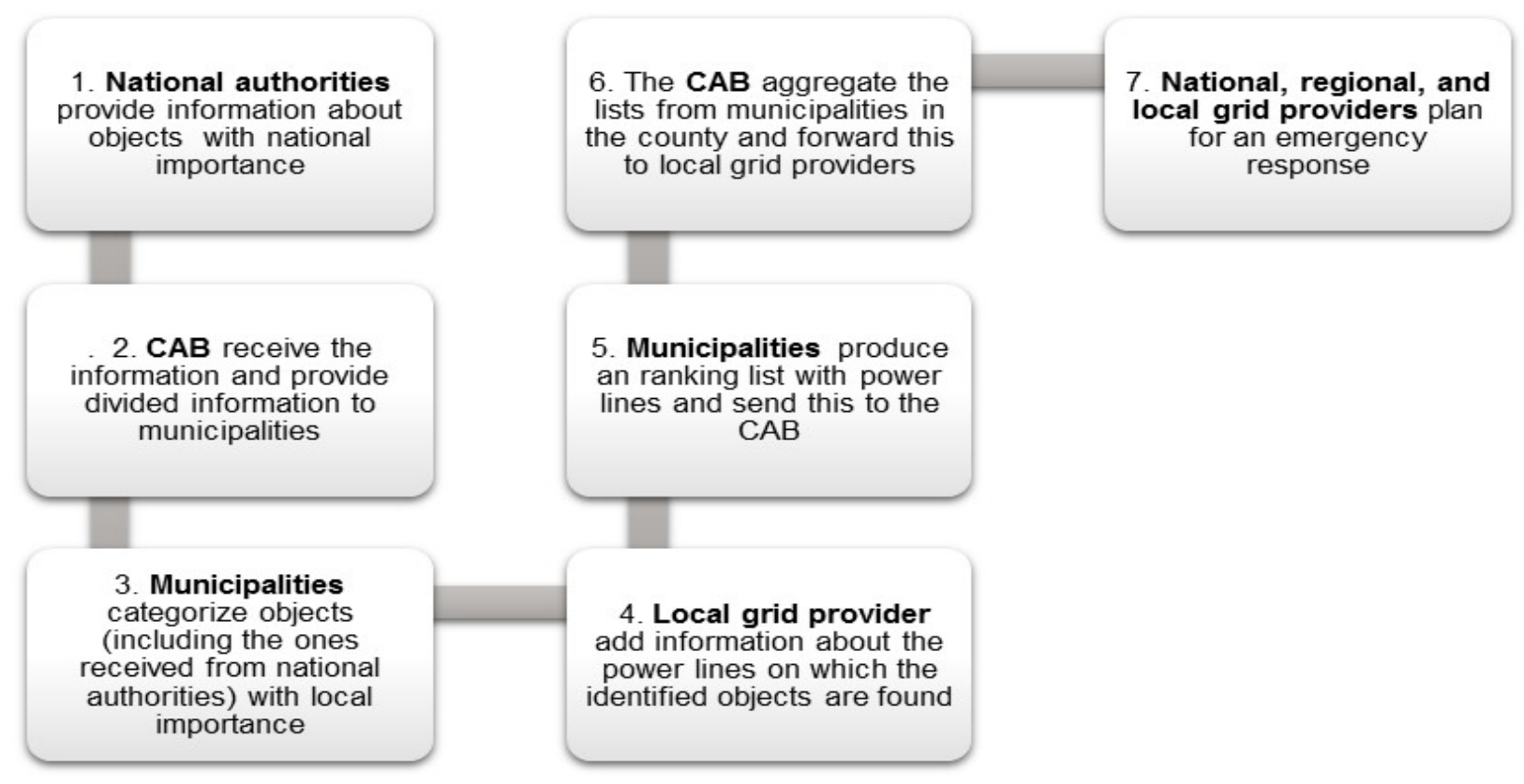

Source: EM, 2013: 8-9 
The process depart from a ranking of vital societal functions, following an eight-point scale (Regulation 2011:931, \$5; EM 2013:13):

1. Electricity users who even in the short term (hours) are of great importance to life and health.

2. Electricity users who even in the short term (hours) are of great importance to society's functionality.

3. Electricity users who in the longer term (days) are of great importance to life and health.

4. Electricity users who in the longer term (days) are of great importance to society's functionality.

5. Electricity users who represent major economic interests.

6. Electricity users who are of great importance to the environment.

7. Electricity users who are of great importance to social and cultural interests.

8. Other electricity users.

Based on the eight priority classes, the government authorities in step (1) identify the vital societal objects that exist within their areas of responsibility. Each authority send information about the objects to the relevant CAB.

In step (2) the CAB divides the prioritised objects that have been identified by the authorities and sends this information to the relevant municipality. In step (3) the municipalities identify vital societal objects within their geographical area. In this step they also take into account the objects identified by the national authorities. Thereafter, in step (4), the municipalities send a list containing information for the various identified objects to the power grid companies, who provide the municipalities with information about the power lines that relate to the identified objects.

In step (5) the municipalities rank the identified power lines based on the ranking (priority class) allocated to the various objects. Thereafter, the municipalities send the lists of the prioritised power lines to the CAB. Finally, the CAB, in step (6), compile the various priorities and produce a common list for the entire county. The receiver of the final list is SvK who produce a national list with objects that are crucial to the electricity supply. Based on this list, it is possible to perform a MFK plan (EM, 2013: 10-11).

STYREL requires collaboration between the CAB and the municipalities. On the other hand, it does not require any sort of formalised collaboration with the government authorities. Consequently, Styrel not a traditional example of network governance process, even though it does contain such elements. In the pilot study in Blekinge County in 2009, the formation of networks was highlighted as an advantage within STYREL: It was stated in the final report from Blekinge County that The networks that are created within Styrel and other similar processes provide conditions for future effective implementation. (Blekinge 2009: 20). The work within STYREL should therefore be coordinated with other activities within, for example, the work with risk and vulnerability analyses. By taking inventory of and identifying vital societal operations, Styrel can contribute to the creation of conditions for a sustainable energy supply. In the final report after the first two county trials, it was found that Styrel provides conditions for public sector-private sector collaboration aimed at achieving "the long-term and sustainable assurance of vital societal needs" (EM 2010: 38).

In a study of the central documents regarding Styrel, Gro冈e et. al (forthcoming) argues that the process can be improved by clarifying the aim and goals of the process. Furthermore, clarification of the flow of information and a clearer explanation of the different phases of the planning process can strengthen the quality of the process. Finally, the actors responsible for identifying and prioritizing the vital societal functions need better understanding of the priority classes in order make informed decisions. This aims to create a sustainable process prior to a possible electrical power shortage. Sustainability and resilience in the power supply during a situation of power shortage is crucial for the society to carry out important societal functions. The next part will discuss resilience and the implementation of strategies aiming for a resilient society.

\section{RESILIENCE AND IMPLEMENTATION}

The concept of sustainable development was first introduced in the Brundtland Report 2010 and was defined as "development that satisfies today's needs without jeopardising the possibilities for future generations to satisfy their needs" (Brundtland \& Hägerhäll, 1988: XX). Sustainable development is often associated with the term resilience. The word resilience derives from Latin resilio, which means to jump back (Klein, Nicholls and Thomalla, 2003). The concept is often defined as the ability to return to an original status after a temporary disruption (see i.e. Holling 1973; Wildawsky, 1991). However, after a disruption, resilience does not necessarily implies that society need to return to the same starting point as before (Handmer \& Dovers, 1996). Resilience often embrace both a set of attitudes on desired actions as well as the development of new opportunities. To identify resilience seems to be less problematic 
than to create it where it does not exist. The ability to react on singular or unique events seems to a common way to conceptualize resilience (Kendra \& Wachtendorf, 2003). Resilience can also defined as the ability of a society or a system to maintain societal functions (i.e. continue to produce) when it has been subjected to chock (Rose, 2007). The concept ca also be seen as just another way of conceptualising change (Miles \& Petridou 2015).

Manyena (2006) argues that the concept of resilience helps us to get a better understanding of the concepts of risk and vulnerability and that the concept is important for an understanding of risk management. The ability to work across border is according to Rhinhard \& Sundelius (2014: 198-203) an important basis for resilience. The author argues that cooperation improves resilience in a crisis since it (i) increases the coordination level, including risk communication, decision-making and policy implementation; (ii) increases the resource distribution; and (iii) increases trust-building and social capital. Resilience can also be compared with the concept of adaptive capacity, which is a measure of the extent to which a society is prepared to react to phenomena such as climate change and its willingness to undertake measures in order to manage such phenomena (see e.g. IPCC 2001; Folke, Carpenter, Elmqvist, Gunderson, Holling \& Walker, 2002; Storbjörk, 2006; Khailani \& Perera, 2013). Boin \& MacDonnell discuss the limits of crisis management in critical infrastructure and the need for resilience. They argue that a crisis in itself do not necessarily lead to change but established policies, procedures, cultures and legitimacies will change during a crisis or disaster (Boin \& MacDonnell 2007).

The implementation of resilience strategies, calls for the creation of a concrete measures, including indications that ensure the evaluation of the system. Furthermore, the actors, including policy makers, businesses etc., need to exchange information and data to ensure the implementation of the strategy. This often requires technical solutions. Finally, it is important to acknowledge and analyze the importance of the timeframes for the actions since these often differs between the actors. (see Bach et.al. 2013)

When it comes to the Styrel policy, the planning process will ensure a sustainable supply of electricity in order to maintain socially important functions during a situation of power shortage. In the end, the aim is also to create a resilient power supply and for society to be able to adopt to a new situation before, during and after a situation of power shortage. In addition to this primary aim, Styrel also gives the actors involved an opportunity to take inventory of vital societal operations and the power supply lines that are of most relevance in the event of an electrical energy shortage.

In order to obtain a resilient policy for power shortage, collaboration is a key factor (Rhinhard \& Sundelius, 2014). Since Styrel is a part of the Swedish crisis management system, it requires cooperation and collaboration between the key actors representing public and private sector. The need for cooperation and for networks is also one of the conclusions to arise from the pilot in Blekinge. The $\mathrm{CAB}$ states that The possibility to undertake an effective and relevant Styrel process is primarily dependent on the ability of people to collaborate. Dialogue, trust, transparency and networking are key watchwords for the creation of an effective process (County Administrative Board of Blekinge, 2009: 3). So what, then, is it that characterises a policy network? The next part will focus on policy networks and discuss the role and importance of the regional hub for the implementation of strategies.

\section{POLICY NETWORKS}

Networks are often characterised by the fact that those who make up the network have common interests in relation to the issue or policy area that forms the basis for collaboration. Consequently, networks often vary in terms of both the degree of internal influence and that which ultimately characterises them. The issue of exactly what constitutes their nature then becomes an empirical question (Rhodes, 1997, p. 39). Research on networks primarily focus on tensions between networks and traditional institutions, as well as on the network's complex decision-making mechanism. Klijn (2008) claims that trust between the actors within a network is crucial, although there is an alarming lack of studies in this area.

According to Rhodes (1997, p. 3) there is often a relationship of mutual dependency between the various actors in the network, something which means that they are in practice self-organising. There are, however, a number of examples in which the parties included are not the once that initiated the formation of the network. One such example is that of the aforementioned river groups, who handle issues relating to floods and high water levels in major waterways. The river groups originated from the Coordination Group for Information regarding High Rivers etc. which was formed at the beginning of the 1990s on the initiative of the actors involved, all of whom saw the need for collaboration. When the river groups were subsequently formed as a result of the River Safety Investigation 1997, these networks operated for a lengthy period of time parallel to the Coordination Group (see Olausson \& Nyhlén, 2017; Petridou \& Olausson, 2017). A study of the river groups in northern Sweden shows that the vague instructions, 
which preceded the formation of the river groups. Combined with differing understandings of the need of the network, this effected the implementation of the policy. Consequently, the different river groups work differently in terms of which actors are involved, the point of focus regarding the collaboration, and which activities and operations that each group encompasses (see Olausson $\&$ Nyhlén, 2017).

Studies on the role of the regional climate and energy planning show that the role of the CAB is crucial for the implementation of a strategy. In order for the process to be accepted and to facilitate the implementation, the CAB needed lead the process and subsequently act as a meta-governor. When the $\mathrm{CAB}$ acted only partly or not at all as a meta-governor, the implementation process became more problematic. (see Palm \& Thoresson, 2014)

Even though Styrel lack some of the characteristics, there are elements of network governance built into the system. This include the planning process and the collaboration between the national, regional and local actors together with the power grid companies. These elements of network governance are particularly visible in step (6), in which the CAB and the municipalities collaborate to produce a well-considered list of prioritised power supply lines for the entire county. However, no formal collaboration with the government authorities is required, since these only deliver a list of prioritised objects broken down by county. As for the river groups, Styrel is enforced upon the actors. The national authorities first identified the need for Styrel, not the included actors. The directive origins from the EM. However, how this effected the implementation of the policy and to what extend Styrel has entailed the formation of policy networks and if the process contribute to a sustainable and resilient power supply system is still to be seen.

\section{METHOD}

This study focus on Styrel as a network and to what extend the process contribute to a sustainable and resilient power supply. Therefore, it is necessary to perform a document study of the outset of the process, the handbooks produced and the evaluations of the pilot and the first round. The documents included are primarily reports and evaluations of the STYREL process since the initiation of the process in 2004. The material consists in part of the handbooks that the EM produced for the two rounds of planning that have been carried out thus far (EM 2011, EM 2014). Also included is the EM's final report from the pilot study in 2007 and the first round of planning in 2011 (EM 2012). Interviews and surveys with representatives from central authorities, CABs, municipalities and power companies comprise the basis for the report. Furthermore, the evaluations of the county trials in Blekinge and Dalarna have also been used (County Administrative Board of Blekinge, 2009; County Administrative Board of Dalarna, 2009), as well as the evaluation of the first round of planning which has been carried out by the CAB in Stockholm (County Administrative Board of Stockholm, 2011). Finally, FOI's report on the power companies' MFK planning (FOI, 2013) is also included.

Furthermore, a survey of the coordinators at the $\mathrm{CAB}$ provides a broad picture on the importance of the process, the usefulness of the process and to what extend there is trust within the networks. The response rate of the survey was $74 \%$ implying that 15 out of 21 coordinators answered. Among these, 58\% has not participated in any of the two rounds of Styrel. Consequently, the result of the survey does not provide us with sufficient information. Therefore, interviews with three coordinators at CAB complement the result of the survey. The interviews is performed in three counties chosen on the basis that they can represent three different types of regions. One representing the rural north, representing rural regions with the specific kind of problems that comes with small population spread out on a geographically large area. One with heavy industries, close to the metropolitan area of Stockholm. Finally, one region with one of Sweden's major cities combined with rural municipalities representing the regions with one dominating municipality. The interviews with the coordinators at the CAB are performed in 2016. The interviews are semi-structured and depart from a number of categories.

\section{STYREL - SUSTAINABILITY AND NETWORK GOVERNANCE}

Societies increasingly dependence of electricity calls for the creation of a sustainable and resilient power distribution. In order to handle a situation of power shortage, the EM developed Styrel in 2010 as a planning process to identify and prioritize socially important objects in the case of power shortage. Since Styrel is a part of the Swedish crisis management system, the CABs are responsible for the coordination. The evaluations after the first round of planning in 2010 showed that the general perception among 
the CABs was that Styrel had contributed to the important work of prioritising vital societal operations and that the process should also be able to be used for other types of activities. Styrel contributes to the crisis management work in each county and play an important role in other contexts, such as e.g. city planning, climate change adaptation and risk industries. The foremost challenges were to be uniting the municipalities in their priorities, and managing dependency chains and deciding how far it is justified to go in the analysis of dependency chains. (EM 2014)

As is shown in the survey of the $21 \mathrm{CAB}$ coordinators (see Gro冈e \& Olausson, 2018) the importance of Styrel scores 4.64 on a 5 -grade scale where 0 stands for no use and 5 for great use. This is also confirmed by the interviews of the three coordinators at the regional level and the xx coordinators at local level.

Tab. 1: The Coordinators at the CAB

\begin{tabular}{llllllll}
\hline & Median & $\mathbf{0}$ & $\mathbf{1}$ & $\mathbf{2}$ & $\mathbf{3}$ & $\mathbf{4}$ & $\mathbf{5}$ \\
\hline Importance of Styrel & 4.64 & 0 & 0 & 0 & 1 & 3 & 10 \\
\hline Usefulness in crisis management & 3.80 & 0 & 2 & 0 & 2 & 6 & 5 \\
\hline Collaboration with & & & & & & & \\
\hline - National agencies & 3.11 & 0 & 1 & 1 & 3 & 4 & 0 \\
\hline - Municipalities & 4.00 & 0 & 0 & 1 & 3 & 4 & 5 \\
\hline Trust in & & & & & & & \\
\hline - National agencies & 2.90 & 0 & 1 & 2 & 4 & 3 & 0 \\
\hline- Municipalities & 3.55 & 0 & 1 & 0 & 3 & 6 & 1 \\
\hline- Energy Agency & 3.90 & 0 & 1 & 2 & 4 & 3 & 0 \\
\hline
\end{tabular}

(Source: Große \& Olausson, 2018)

The usefulness of Styrel however does not get as high scores as the importance of the system. In the survey, usefulness scores $3.8 \mathrm{n}$ the 5-grade scale and the interviews also confirms that the usefulness of the system as it is designed today is not seen as equal obvious as the importance of the system. In all three interviews, the lack of feedback that is built into the system is a major critique. It is also argued that there is a risk for a copy-and-paste behaviour since the local coordinators were not given feedback in the first round. The lack of feedback and the risk of copy-paste both reviles problems that is built into the planning process and that could endanger the usefulness of the plans produced during the process. This in turn could question whether or not Styrel contributes to a sustainable and resilient power supply.

The problems of getting information from actors at the national level is also seen as problematic, both in the survey and in the interviews. When it comes to trust in the national agencies, the survey shows a score of 2.9 while the trust in the municipalities score 3.55. The trust in the <Energy Agency score 3.9. The inter views with the coordinators at the regional level reviles differences between the three regions. The trust between the actors in the rural county with fewer municipalities seems to be higher than in the more populated, but geographically smaller county with more than four times as many municipalities. The lack of trust between the actors included also might risk the sustainability and the resilience of the planning process. The differences in how the process was carried out also differs between the counties.

The planning process is described in the Handbook for Styrel and the interviews show that all three of the CABs selected have used the planning model as it is described in the handbook. However, some deviations from the planning model can been identified in all three cases. The most common explanation is the deviation from the timetable. The major reason for this, according to the interviews is a consequence of the fact that the original timetable was far too optimistic. The three coordination officers argues that there was a risk that an over-optimistic timetable had led to the work of the municipalities and CABs having to be performed too hastily, which in turn had led to a widespread occurrence of "copy and paste" behaviour out in the municipalities.

During the second round of Styrel planning in 2014, the role of the CABs had been changed. This time their role was not to weighing up of the priorities at a county level but more to compile the planning that had been performed in the municipalities. 
During the first round, the CAB knew what objects that had been identified along the power lines. In the second round, the lists only complied power lines without any objects. However, this change in role was not adhered to in one of the counties, where the final prioritisation was more a result of a "group project" between the municipalities, the regional council and the CAB, using an already existing network. The three highest priority classes were thereto distributed proportionately between the municipalities involved. According to the coordination officer in question, these municipalities were in consensus regarding this departure from the original planning process. "Well, how else were we supposed to work? It's, like, just one long bloody list".

In one of the counties, representatives from the CAB chose to use the already existing five parts of the county, with the aim of being able to implement the planning process as smoothly as possible. In doing do they also chose to utilise the networks that already existed. The consequence of this choice was a smoother work process, but one in which the municipalities involved only had an overview of their own part of the county, not an overall view of the entire county.

Improved network governance and increased resources were two improvement measures that had been highlighted by Civil Defence Directors at the CABs (see Wimelius \& Engberg). When it comes to Styrel, however, no extra resources have been allocated to the operations. The interviews show that, during the first round of Styrel planning, all three CABs allocated extra resources to the implementation of the process, but during the second round of planning the assignment was carried out within existing operational capacity. Unlike the weak governance associated with the formation and coordination of the river groups (see Olausson \& Nyhlén), the organisation of the Styrel process has been more clearly structured from the very beginning. The governance mechanism was also made even clearer in-between the first and second rounds of Styrel planning, through the new handbook that was developed (see EM)

When it comes to network governance, the importance of working within networks that already exist was emphasised in all three cases. The evaluation that was carried out in 2011 after the first round of Styrel planning shows that the CABs had perceived at the time that the Styrel process had contributed to improved collaboration within existing networks (The EM 2012). The crisis preparedness networks that already existed were utilised in all three cases. However, the structure of these networks is different in the three counties. The foremost reason for these differences is a result of the differences in size between the three counties. The two smaller counties both worked in a collective manner, and they arranged, among other things, meetings involving representatives from all of the municipalities involved. They also arranged meetings within existing networks. In the larger county, they were divided up into four or five different groups.

Something that has also influenced the planning process and its implementation when it comes to keeping to the original planning process is that two of the counties are dominated by one major municipality, with all of the other municipalities in these counties being significantly smaller in terms of population. The coordination officers mean that, in theory, this could affect the planning process and the legitimacy of its results.

In the planning process, there is no built-in feedback mechanism between the CABs and the municipalities. Once the municipalities have submitted their planning proposal, it is the role of the CAB to compile a list of priorities and thereafter send this information directly to SvK. (cf. steps 5 and 6 in the process description, see figure 1). In one case, the CAB to the municipalities provided feedback, and a weighted priority list was produced via a "group project" between the municipalities and the CAB.

In summary the CABs initially had an ambition to follow the pre-determined process for Styrel, but in all three cases certain departures from the original process have occurred. In some instances, this has primarily had to do with not adhering to the original timetable. In other cases there have been more comprehensive departures from the process, whereby the CABs have not only acted as coordinators and compilers of information from the municipalities, but they have also actively taken part in the discussions between the municipalities and have carried out the work in the form of a "group project".

When it comes to the utilisation of existing networks, all three have made use of networks that were already in place. The differences in how the three have chosen to do this is primarily down to practical reasons of size in terms of population, geographical area and the number of municipalities in the county. In two of the counties, the process has been carried out through collaboration between all municipalities, while in the third case the county has been divided up into groups.

\section{DISCUSSION AND CONCLUSIONS}

Planning for a resilient and sustainable electricity supply gets more important in our increasingly electricity dependent society. In the case of a power shortage, there need to be plans to ensure that socially important objects gets electricity. Sweden implanted the 
Styrel policy in 2010. In the process, the CAB plays an important role as coordinator at a regional level. However, this study reviles problem related to the implementation of the process. According to Bach et.al. (2013), the endurance of evaluation, the exchange of information, and the importance of the actors' timeframes are important to ensure the implementation of a resilience strategy. However, the study shows that Styrel as a process does not necessarily respond to these requirements and thereby do not necessarily contribute to the creation of a sustainable energy supply in the way described by the EM's assignment. Rhinhard \& Sundelius (2014) argues that in order to implement the policies aiming for resilience during a crisis, it is important to cooperate across borders, increase the resource distribution and the trust-building between actors. Even though Styrel include an element of private-public cooperation, the process do not involve any comprehensive cooperation or networking between the actors. The study also reviles lack of trust between the actors in the planning system. At best, this implies that Styrel creates conditions for guaranteeing that vital operations in society are supplied with energy during an energy shortage. However, this requires quality assurance of the planning work that has been assigned to the municipalities in accordance with the Styrel regulations.

During the interviews it has become evident that the process has not been followed to the full and that a certain form of "copy and paste" behaviour has occurred between the two rounds of Styrel planning. Since there can be no guarantees that the information about vital societal operations that was produced prior to the first round of Styrel planning is still accurate and relevant three years later, there is also a risk that the documentation does not fully reflect the intentions and the priorities of the municipalities and authorities.

In the evaluation of the initial trials of Styrel, emphasis was placed on the importance of public sector-private sector collaboration and the creation of networks with the aim of successfully performing the duties that Styrel has imposed on municipalities, regional/ county councils and CABs as well as on network operators. However, the study shows that the three CABs have not created new networks for the purpose of identifying vital societal operations. This is also something that is highlighted in the critical review of Styrel by Grosse et. al (forthcoming). Private actors and civil society representatives are not included in the planning model or the handbook for the process that the EM has produced. On the other hand, there is nothing to prevent the municipalities or the CABs from including private actors and civil society representatives in the work involving the prioritisation of vital societal operations, with the aim of creating as broad a decision-making basis as possible. Even the evaluations that have been carried out after the pilot study in 2007 and the first round of Styrel planning in 2011 show that only limited contact has occurred between the CABs and private actors. Olausson \& Nyhlén (2017) show that vague instructions in the implementation of a policy can imply a range of different interpretations of the policy and thereby also different ways of implementing the policy at stake. During Styrel, some form of collaboration has occurred but the implementation of this collaboration differ between the municipalities and between the counties. The collaboration has primarily been with private power companies, something that the process itself requires (EM 2012: 36). Instead, use has been made of existing networks in which only representatives from public sector actors are included. This follows the theories by Rhodes (1997) that in order for networks to be successful, the actors themselves must identify the need of the networks. This leads to a more effective work process, since the actors involved are already familiar with one another and have an established way of working. There is, however, a risk that relevant information will be lost due to the absence of representatives from the network operators and from private actors responsible for vital societal production, private care providers, etc. The work method employed thus requires the public actors within the municipalities, regional/county councils and CABs to have good knowledge about the private companies. Whether or not this is the case during the inventory and identification of vital societal operations out in the municipalities remains to be seen. However, there are no such indications based on that which has been revealed during the interviews with the coordination officers at the three CABs.

During Styrel process, $\mathrm{CAB}$ act as coordinator. However, the role does not include any other responsibility than to comply the lists of power lines produced by the municipalities. Palm \& Thoresson (2014) emphasize the importance of the CAB acting as a meta-governor in the work with regional climate and energy planning. However, in the Styrel process the role of CAB is not the one of a meta-governor. Instead, the role is limited and thereby weak since the CAB does not know what objects are on the power line and thereby cannot assess the importance of the different power lines themselves.

Styrel can be viewed as part of the creation of a sustainable energy supply, even during periods of electrical energy shortage. The study regarding the coordination responsibility of the CABs shows that the implementation of Styrel does not entirely follow the regulations that have been created through the process. In particular the risks created by a sort of "copy-and-paste" behaviour could impact on the conditions for a sustainable energy supply during a situation of electrical energy shortage. Based on the concept of resilience, in the meaning of maintaining society's functions when it has been subjected to chock, the study of the CABs' coordinative 
function shows that there is a risk that vital societal functions cannot be maintained during an electrical energy shortage. There are, at the very least, no guarantees that the Styrel process, such as it has been carried out, will guarantee neither a resilient nor a sustainable electrical energy supply. Nor does it seem that Styrel has created any formal or established type of collaboration between private sector and public sector actors in practice. The lack of trust between the included parties could easily affect the planning process and the result of the identifying and prioritizing of socially important objects. To what extend the lack of trust influence, is yet to be studied. Whether any formal or established type of collaboration takes place at municipal level remains to be studied.

\section{ACKNOWLEDGEMENT}

This study forms part of the research project 'From authority to citizens and back - A study of the interaction and communication in the context of Styrel' funded by the Swedish Energy Agency.

\section{REFERENCES}

Bach, C., Bouchon, S., Fekete, A., Birkmann, J., \& Serre, D. (2013). Adding value to critical infrastructure research and disaster risk management: the resilience concept. SAPI EN. S. Surveys and Perspectives Integrating Environment and Society, (6.1).

Boin, Arjen, Louise K. Comfort, and Chris C. Demchak. "The rise of resilience." Designing resilience: Preparing for extreme events (2010): 1-12.

Boin, A., \& McConnell, A. (2007). Preparing for critical infrastructure breakdowns: the limits of crisis management and the need for resilience. Journal of Contingencies and Crisis Management, 15(1), 50-59.

Brundtland, G. H., \& Hägerhäll, B. (1988). Our Common Future: Report of the World Commission on Environment and Development under the chairmanship of Gro Harlem Brundtland. Prisma.

Carlsson, L. (2000). 'Policy networks as collective action'. Policy studies journal, 28(3), 502-520.

Cohen, F. (2010), "What makes critical infrastructures Critical?", International Journal of Critical Infrastructure Protection, Vol. 3 No. 2, pp. 53-54.

EM, 2006. Stormen Gudrun. Vad kan vi lära av naturkatastrofen 2005? [Storm Gudrun. What can we learn from the natural disaster of 2005?] ET2006:02.

EM, 2007. Utvärdering av stormen Per - aktörsvisa sammanställningar av intervjuer och analyser [Evaluation of Storm Per - actor-based summaries of interviews and analyses]. ER 2007:37.

EM, 2010. Styrel: Prioritering av elanvändare vid elbrist. Slutrapport från Energimyndighetens Styrel-projekt åren 2008-2009 [Styrel: Prioritisation of electricity users during an electricity shortage. Final report from the EM's Styrel project 2008-2009]. ER 2010:15
EM, 2012. Slutrapport från Energimyndighetens Styrel-projekt [Final report from the Swedish Energy Agency's Styrel project]: ER 2012:04, 73 pp.

EM, 2014. Styrel: Handbok för Styrels planeringsomgång 2014-2015 [Styrel: Handbook for Styrel's 2014-2015 round of planning]. ET2013:23, $62 \mathrm{pp}$.

Enander, A., Hede, S., \& Lajksjö, Ö. (2015). 'Why worry? Motivation for crisis preparedness work among municipal leaders in Sweden'. Journal of Contingencies and Crisis Management, 23(1), 1-10.

Fell, A. (2008), Nätverksstyrning för en hållbar utveckling: en fallstudie av Energimyndighetens program Uthållig kommun 2003-2007 [Network Governance for sustainable development: a case study of the Swedish Energy Agency's program Sustainable Municipality 2003-2007]. Luleå: Luleå University of Technology

FOI, 2013. Elnätsföretagens MFK-planering. Enstudie avelnätsföretagens möjligheter att genomföra manuell förbrukningsfrånkoppling baserad på Styrel [The power companies' MFK planning. A study of the power companies' possibilities to perform manual consumption disconnection based on Styrel]. FOI-R-3797.

Folke, C., Carpenter, S., Elmqvist, T., Gunderson, L., Holling, C. S., \& Walker, B. (2002). 'Resilience and sustainable development: building adaptive capacity in a world of transformations', AMBIO: A journal of the human environment, 31(5), 437-440.

Ghanem, D.A., Mander, S. and Gough, C. (2016), "'I think we need to get a better generator". Household resilience to disruption to power supply during storm events", Energy Policy, Vol. 92, pp. 171-180.

Große, C. \& Olausson, P.M. (2018) Multi-Level Planning Systems for Critical Infrastructure Protection: Planning for Power Shortage in Germany, Sweden and USA. Paper presented at MPSA conference, Chicago. 
Große, C. \& Olausson, P.M. (2018) Swedish Multi-Level Planning System for Critical Infrastructure Protection: The Regional Core. ESREL, 2018.

Große, C., Olausson, P.M., Larsson, A., Björkqvist, O., Danielsson, E., Wallman-Lundåsen, S., Nyhlén, J. (forthcoming). Perspectives on Collaboration and Decision-making in Response Planning to Power Shortage: A Critical Discourse of the Swedish Policy.

Gustavsson, E. (2008) Mellan det lokala och det globala: klimat, kommuner, nätverk [Between the local and the global: climate, municipalities, networks]. Diss. Örebro. Örebro University Press.

Handmer, J. W., \& Dovers, S. R. (1996). A typology of resilience: rethinking institutions for sustainable development. Industrial \& Environmental Crisis Quarterly, 9(4), 482-511.

Holling, C.S. (1973). Resilience and stability of ecological systems. Annual Review of Ecological Systems 4, 1973: 1-23.

IPCC 2001: Climate change 2001: the scientific basis. Contribution of Working Group I to The Third Assessment Report of the IPCC. Cambridge: Cambridge University Press

Johansson, V. (2015) 'Johansson, V. (2015). 'Policy networks-A threat to procedural and expert-based decision making and the quality of public risk decisions?', International Journal of Critical Infrastructure Protection, 9, 3-12.

Kendra, J. M., \& Wachtendorf, T. (2003). Elements of resilience after the world trade center disaster: reconstituting New York City's Emergency Operations Centre. Disasters, 27(1), 37-53.

Khailani, D.K., and Perera, R.. 'Mainstreaming disaster resilience attributes in local development plans for the adaptation to climate change induced flooding: A study based on the local plan of Shah Alam City, Malaysia', Land Use Policy 30.1 (2013): 615-627.

Klein, R. J., Nicholls, R. J., \& Thomalla, F. (2003). Resilience to natural hazards: How useful is this concept? Global Environmental Change Part B: Environmental Hazards, 5(1-2), 35-45.

Lidén, G., Nyhlén J. \& Nyhlén S. (2015) 'Forced cooperation from above: the case of Sweden's Establishment reform', Policy Studies, Vol. 37 No. 3, pp. 468-486

Länsstyrelsen i Blekinge (2009) Styrel Slutrapport Länsförsök Blekinge [County Administrative Board of Blekinge (2009) Styrel Final Report County Trial Blekinge], 20090924, Karlskrona.

Miles, L., and Petridou, E. (2015). Entrepreneurial Resilience: Role of Policy Entrepreneurship in the Political Perspective of Crisis Management. In R. Bhamra (Ed.), Organisational Resilience: Concepts Integration and Practice (pp. 67-81). Boca Raton, FL: CRC Press.
Manyena, S. B. (2006). The concept of resilience revisited. Disasters, $30(4), 434-450$.

MSB (2015), Gemensamma grunder för samverkan och ledning vid samhällsstörningar, Myndigheten för samhällsskydd och beredskap [Common grounds for collaboration and management during disruptions to society, The Swedish Civil Contingencies Agency] (MSB), Karlstad.

Olausson, P. M., \& Nyhlén, J. (2017). Organization and Decision-Making in Enforced Networks: The River Groups in Northern Sweden. Journal of Contingencies and Crisis Management.

Palm, J., \& Thoresson, J. (2014). Strategies and implications for network participation in regional climate and energy planning. Journal of Environmental Policy \& Planning, 16(1), 3-19.

Petridou, E., \& Olausson, P.M (2016). Policy Entrepreneurship and Policy Transfer: Flood Risk Governance in Northern Sweden. Central European Journal on Public Policy 2017; 11(1).

Rhinard, M., \& Sundelius, B. (2010). The limits of self-reliance: International cooperation as a source of resilience. Designing resilience: Preparing for extreme events, 196-219.

Rhodes, R. A. W. (1996) The New Governance: Governing without Government in Political Studies, Vol. 44, No 4, pp. 652-667.

Rhodes, R. A. W. (1997) Understanding Governance: Policy Networks, Governance, Reflexivity and Accountability in Administrative Theory \& Praxis, Vol. 20, No. 3 (Sep., 1998), pp. 394-396

Rose, A. (2007). Economic resilience to natural and man-made disasters: Multidisciplinary origins and contextual dimensions. Environmental Hazards, 7(4), 383-398.

Sørensen, E., \& Torfing, J. (2005). 'The democratic anchorage of governance networks', Scandinavian political studies, 28(3), 195-218.

Sørensen, E., and Torfing, J. (2007) Theories of democratic network governance. Palgrave Macmillan.

Storbjörk, Sofie (2006) Klimatanpassning i Sverige: Drivkrafter och utmaningar för riskhantering och fysisk planering [Climate adaptation in Sweden: Driving forces and challenges for risk management and physical planning]. Linköping: Centre for Climate Science and Policy Research

SvK Svenska Kraftnät, 2016. The electricity balance in the Swedish power market during the winters of 2015/2016 and 2016/2016 (in Swedish) (No. 2016/1129). Sundbyberg.

Swedish Civil Contingencies Agency (2010), Styrel - inriktning för prioritering av elanvändare [Styrel - orientation for prioritisation of electricity users]. 
Torfing, J. (2005). 'Governance network theory: towards a second generation', European political science, 4(3), 305-315.

Wildavsky, A. (1991) Searching for Safety. Transaction, New Brunswick, NJ.

Wimelius, M. E., \& Engberg, J. (2015). 'Crisis Management through Network Coordination: Experiences of Swedish Civil Defence Directors'. Journal of Contingencies and Crisis Management, 23(3), 129-137 